\title{
Learning Outcomes and Attitudes of Mattayom 3 (Grade 9) Students toward Studying Science in English
}

\author{
S. Charoenwet ${ }^{1}$ I. Zurida ${ }^{2}$ \\ ${ }^{1}$ Suratpittaya School Surat Thani 84000 Thailand salubsri@gmail.com \\ ${ }^{2}$ University Sains Malaysia Penang Malaysia zurida@usm.my
}

\section{Abstract}

The importance of English language has increasingly gained more attention in the Thai education system, particularly in the coming ASEAN Community scheme in 2015. The aim of this study is to investigate the results of integrating English in teaching science in the context of Thai education. Grade 9 students from secondary school in Multilanguage Program (MLP) participated in the enriched program of learning science using English language as a medium of communication. The unit taught was Genetics and learning materials in English including the test were provided. Learning outcomes and students' attitudes were examined after 18 periods of learning activities. The content test in Genetics was administered in Thai language to this group of students similar to those who were in the normal program in order to assess their knowledge regarding the subject content they have learned. The results showed that the posttest score was statistically higher than the pretest's at the level of 0.05 with the average percentage of pretest and posttest score 47.60 and 72.50 respectively. The average score from the assessment test using the Thai exam paper provided satisfying results with the average percentage of 82.58 . The data from the questionnaires revealed positive attitudes of students participating in this program. However, it is found that supplementary
\end{abstract}

hours in Thai are apparently required to promote understanding and in-depth learning of the science content.

Keywords: Learning science, Integrated English learning, Science in English, Students' attitudes

\section{Introduction}

English is known as the global language and is used for communication among people who are not native speakers in the globalization world. It is estimated that the number of people speaking English either as the first language or the second worldwide is over a billion [1]. In the digital world, English becomes the key to access information and even open the opportunity for success in various social network, for example business, education, entertainment or investment. The importance of English is increasingly obvious not only in western countries but also in the East particularly in Southeast Asia where different languages are used by different ethnic groups. Moreover, it is undeniable that English is not only known as a tool for communication but practically used for learning in the context of information acquiry regarding the platform of digital literacy.

In the year 2009, the plan of uniting countries in Southeast Asia in terms of economics, education and culture was tentatively initiated. A particular part of 
the dialogue among these ASEAN countries includes the blueprint of the ASEAN Economic Community (AEC) platform in 2010 [2]. The AEC scheme is an agreement established by ten countries in Southeast Asia India, China and Korea included. The main goal of the AEC scheme focuses on regional economic integration and cooperation in human resources development and capacity building, as well as enhancing infrastructure and communication connection in financial and trading in all member countries [3]. The operation of the ASEAN scheme in the country members will certainly broaden the boundary of communication and bring along a free flow of not only products in trading but also human resources. It is undeniable that the language that will be used in this community is basically English.

The policy of using English as a medium of learning in schools has been introduced into Thai education system for a certain period of time. The programs such as English Program (EP), Mini English Program (MEP), focus on improving students' competence in English communication. Furthermore, to accelerate using English, the year 2012 is announced as English speaking year to encourage using English as well as to encourage Thai people to learn and use English in their daily life [4].

English is the previously introduced in Thai educational curriculum as a foreign language. Although it has been known for decades, that English increasingly played an important role in global communication, not until recently that Thailand has earnestly put the policy of integrating the language in curriculum into practice. It is strongly recommended that English is included in teaching core subjects in each level of Thai curriculum. It is also emphasized that students should be able to use English to communicate their ideas effectively regarding the World Class Scheme [5].

According to the Thai Ministry of Education, the special programs i.e. English Program (EP) and Mini English Program (MEP) are readily provided in particular schools with the hour of studying varieties of subjects in English, approximately sixteen hours per week [4]. The subjects that are taught in English include mathematics, science, social studies, PE, as well as English. The program is normally based on Thai curriculum which is likely to be content based learning [5]. It is hard to predict if these programs are potentially building up English proficiency while maintaining knowledge based learning that suits the Thai education system.

In the past few years, a particular program i.e. English for Integrated Studies (EIS) has been introduced for some programs with the aim to encourage the use of English in teaching science and mathematics by Thai teachers. EIS program has been claimed to be literally successful in schools that have joined the group of EIS scheme [6].

Besides the particular programs mentioned earlier, the World Class Standard scheme was recently introduced to the first 500 Top Star or Smart schools under the Office of Basic Education Commission in 2011 [7]. The main objective of the scheme is to alleviate the quality of students in becoming prospective world citizens. The main goals of interest in building up the quality of World Class citizen includes the ability to communicate in other languages, including English.

This study presents the results of the investigation into teaching science for Grade 9 students in English by a Thai teacher. The methods used in this study include one group experiment with pretest, posttest and the knowledge based test. Additionally, students' attitudes 
were examined through self-reported questionnaires.

\subsection{Multilanguage Program}

Multilanguage Program (MLP) is a special program under the Office of Academic Affair, Suratpittaya school, Surat Thani, Thailand. The program was established in 2007 and currently, there are 166 students in the program. The main aim of MLP is to nurture students who are potentially interested in languages three languages, i.e. Thai, English and Chinese. The curriculum used is practically aligned with the core curriculum in the normal program. Apart from English and Chinese that have been taught by native speakers, these students also study science and maths in English [8].

\section{Matherails And Methods}

\subsection{Participants and setting}

Thirty-two of Mattayom 3 (Grade 9) students studying in Multilanguage Program (MLP) Suratpittya school, Thailand participated in this study. The subject that was taught in English was Science on the topic Genetics in the first semester of the academic year 2011.

\subsection{Procedure}

Six lesson plans of 18 periods for the unit of Genetics including Mendel's experiment, Gene \& Chromosome and Mendel's Laws were prepared. Students were assigned to participate in classroom learning activities which include both lecture and hands on activities. All materials used in the classroom as well as teaching instructions were in English. Prior to the first learning session, students were administered the pretest in English with 30 items. The post test was carried out similarly at the end of the lesson. Students were assessed on the content knowledge by test in Thai. This test was also used by students in the normal program. The Thai exam paper was provided by Thai science teachers. Additionally, a 10-item self-reported questionnaire was distributed to investigate students' attitudes toward learning science in English with the Thai teacher.

\subsection{Research instrument}

The research instruments used in this study were the content test in Thai and a self-reported questionnaire. The pre and post test consisted of 30 items in English whereas the Thai version contained 35 items. Both tests were based on the content that students had learned. The 5point Likert scale self- reported questionnaire contained 10 items.

\subsection{Data collection}

Three sources of data that were collected in this study, the pretest and posttest score that were administered prior to the class and at the end of the last teaching session, the score of assessment test for Thai exam paper and lastly, the students' attitudes survey.

\subsection{Data analysis}

Average scores of the pretest and posttest was calculated and the comparison t-test analysis was done using SPSS version16 software. The average assessment test scores were calculated and compared to the standard benchmark. Students' attitude questionnaires consisted of 10 items and were quantitatively analyzed using SPSS version 16 software.

\section{Results}

The results obtained from this study were divided into two parts. The first part includes the results of learning outcomes that were the pretest and posttest scores and assessment test scores. The second part was the results from the self-reported 
questionnaire. The comparison between the pretest and posttest score of students showed a statistically significant difference at the level of .05. The average score of the pretest is $47.60 \%$ compared to $72.50 \%$ in the post-test.

The average assessment test score in the Thai version is $82.58 \%$. The highest score was $94.29 \%$ whilst the lowest was $57.14 \%$. A total of $78.12 \%$ students exceeded the score of 80 percent of the full score. Hence, in general, students passed the test with satisfying score in the assessment test.

The analysis of students' attitudes toward learning environment indicated that students have positive attitudes to studying science in English with the Thai teacher at the average rate of 4.07.

\section{Discussion}

It is obvious from this study that using English as the medium of communication to teach science based on Thai core curriculum (B.E. 2551) for Mattayom 3 (Grade 9) students is practically possible. The output from this study is not only in the learning materials in English on the unit of Genetics but also created a challenge for the teacher as well as students who were apparently engaged in this teaching session.

According to the learning outcomes, it is found that students were able to understand the difficult science terminology through English at a certain level. The average score of the posttest is statistically higher compared to that of the pretest. This indicates students are competent to learn complicated science topic using the second language. The score resulted from the knowledge based test in Thai also consequently showed ability of transforming understanding from one language (English) to the other (Thai). The finding is not unusual as it has been reported that learning is a process of understanding the content and implementing knowledge in provided context [9]. Hence, when students are able to understand the content even though it is delivered in English, The language is no longer a barrier no matter how difficult the terms and conditions are.

Learning science through English can probably be seen as a challenge and make students try harder. It is previously found that students feel more engaged in the lesson when they felt that the goal is worthwhile pursuing. The practice is aligned with the scheme of nurturing gifted students who have potential in learning to maximize their ability to cope with different learning setting [10].

Interaction between the teacher and learners was different from the classroom that was taught by foreign teachers in terms of management and assistance provided to students during the learning activity. Students paid more attention to the given task and were more engaged similar to general Thai classes except the language used. It can be claimed that teaching instruction is likely to be in the Thai style while communication was carried out in English. This unique style consequently created effective learning environment for students in harmonious ambience. The results from knowledgebased test indicated that students were competent in improvising knowledge that they have learned in English

Generally, students perceived this style of learning beneficial and meaningful to them as shown by the positive response with a rather high rating score. This could be reasonably due to the hours of English as indicated by the program. Students are therefore, familiar with the language and hence, they tend to take learning information as well as instruction in English naturally. This kind of interaction can also be similarly observed in other enriched English 
programs where students are exposed to more than 15 hours of English per week [4]. However, unlike those programs, learning activities and instructions in this study were carried out by a Thai teacher who is proficient in English. Classroom setting is seen as a traditional Thai class with English used as the medium of communication.

\section{Conclusion}

This study investigated the use of English to teach science content to lower secondary students in Suratpittaya School, Surat Thani, Thailand. 32 Mattayom 3 students (Grade 9) participated in the learning of science through English by a Thai teacher. Teaching materials used in this study were prepared in English. The content of science on Genetics was based on the core curriculum which focused mainly on knowledge. The pretest and posttest scores were compared and the test paper in Thai was administered. Students' attitudes were also examined through a self-reported survey questionnaire to obtain students' perspective regarding the teaching platform. The results showed a promising possibility of learning science in English in accordance with the Thai core curriculum. This study shows satisfactory results both in learning outcomes as well as students' attitudes. However, tutorial class in Thai is eventually required to supplement the regular classes so as to ensure that the content is covered. The results from this study not only imply the potential of learning platform of science in English to a group of students that are quite keen on the language but also provide essential information of teaching science using English as a medium. Further research in this area is required in order to explore the effectiveness of learning to a broader extent.

\section{Refferences}

[1] http://www.thailand teaching. asia/ education-thaland

[2] http://www.ftinakornpathom.or.th

[3] http://www.aseansec.org.

[4] Department of Policy and Planning, The Office of Basic Education Commission, "The Practice of Establishing Special program in Basic Education", 2010.

[5] Thailand Education Act, BE.2551 Office of Basic Education Commission, 2010.

[6] https://sites.google.com/site/surapon geist

[7] http://www.phibun.ac.th/documents/ world class.pdf

[8] Suratpittaya school, "MLP Program" School Curriculum, 2010.

[9] W. Marisa, Report on Students' Potential Development in English Program., 2010.

[10]P. Chaleowsri, The Office of Teacher Council, The Development of Education Standard for Gifted Students, 2011. 